\title{
HUBUNGAN PEER AND PARENT ATTACHMENT DENGAN GANGGUAN PERILAKU MAKAN PADA REMAJA SMA
}

\author{
Maria Yuliana', Mustikasari' ${ }^{2, *}$ \\ ${ }^{1}$ Mahasiswa Ilmu Keperawatan, Fakultas Ilmu Keperawatan, Universitas Indonesia, Kampus RIK \\ UI, Jl. Prof. DR. Bahder Djohan, Pd. Cina, Beji, Kota Depok, Jawa Barat, 16424, Indonesia \\ ${ }^{2}$ Dosen Ilmu Keperawatan, Fakultas Ilmu Keperawatan, Universitas Indonesia, Kampus RIK UI, Jl. \\ Prof. DR. Bahder Djohan, Pd. Cina, Beji, Kota Depok, Jawa Barat, 16424, Indonesia \\ *)E-mail: mustikasari@ui.ac.id
}

Diterima: Juli 2018, diterbitkan: Agustus 2018

\begin{abstract}
ABSTRAK
Remaja mengalami pertumbuhan dan perkembangan fisik serta psikologis yang pesat. Hal ini membuat remaja rentan mengalami masalah kesehatan, salah satunya gangguan perilaku makan. Salah satu faktor yang memengaruhi yaitu peer attachment dan parent attachment. Tujuan penelitian: untuk mengetahui adanya hubungan peer dan parent attachment dengan gangguan perilaku makan pada remaja SMA. Metode: Penelitian menggunakan desain cross sectional kepada 65 responden yang diambil berdasarkan purposive sampling. Kriteria responden penelitian yaitu remaja usia 15-17 tahun dan mengalami gangguan perilaku makan. Gangguan perilaku makan diidentifikasi menggunakan alat ukur The Eating Attitudes Test-26 (EAT-26), sedangkan attachment diukur dengan The Inventory of Peer and Parent Attachment (IPPA) yang valid dan reliabel. Penelitian ini telah dinyatakan lolos kaji etik oleh Komite Etik Penelitian Fakultas Ilmu Keperawatan Universitas Indonesia. Hasil: penelitian menunjukkan ada hubungan peer attachment dengan gangguan perilaku makan ( $p=0,000 ; \mathrm{r}=0,459)$, dan ada hubungan parent attachment dengan gangguan perilaku makan ( $p=0,020$; $\mathrm{r}=0$,288). Kesimpulan: Rekomendasi adalah sekolah dapat memaksimalkan upaya membangun perilaku hidup sehat dengan mengadakan penyuluhan secara berkala berkaitan dengan berat badan ideal, perilaku makan yang baik, dan gizi seimbang
\end{abstract}

Kata Kunci: gangguan perilaku makan, parent attachment, peer attachment, remaja

\section{CORRELATION BETWEEN PEER AND PARENT ATTACHMENT WITH DISORDERED EATING BEHAVIORS IN HIGH SCHOOL ADOLESCENTS} \section{ABSTRACT}

Objective: This study is aimed to determine the correlation between peer and parent attachment with disordered eating behaviors in high school adolescents. Methods: Its design was cross-sectional with samples and selected through purposive sampling technique.The Criteria of respondents were adolescent aged 15-17 years and experienced disodered eating behaviors._Disordered eating behaviors were identified using the The Eating Attitudes Test-26 (EAT-26), while attachments were measured by The Inventory of Peer and Parent Attachment (IPPA). Both of them are valid and reliable. This research has been declared escaped ethical review by Research Ethics Committee Faculty of Nursing University of Indonesia. Data was analyzed with pearson correlation test. Results: The results showed there were a correlation between peer attachment and disordered eating behaviors $(p=0,000 ; r=0,459)$. Also, there were a correlation between parent attachment and disordered eating behaviors ( $p=0,020 ; r=0,288$ ). Disscussion: Recommendation is schools can maximize efforts to build healthy lifestyles by conducting periodic counseling related to ideal body weight, good eating behavior, and balanced nutrition.

Keywords: adolescent, disordered eating behaviors, parent attachment, parent attachment 


\section{LATAR BELAKANG}

Remaja merupakan masa transisi kritis dari anak-anak menuju dewasa karena pada masa ini terjadi kematangan pertumbuhan dan perkembangan fisik serta psikososial yang sangat cepat. Menurut data Sensus Penduduk 2013, tercatat jumlah remaja mencapai 43,5 juta jiwa atau sekitar $18 \%$ dari keseluruhan populasi di Indonesia (Kementrian Kesehatan Republik Indonesia, 2016). Periode remaja dimulai ketika anak-anak sudah mengalami pubertas sekitar usia 10 hingga 13 tahun (Steinberg, 2014). Menurut Hockenberry \& Wilson (2015), rentang usia remaja yaitu 11 tahun hingga 20 tahun yang kemudian dibagi menjadi remaja awal (11-14 tahun), remaja tengah (15-17 tahun), dan remaja akhir (1820 tahun). Pertumbuhan dan perkembangan remaja yang terjadi menjadikan remaja rentan mengalami masalah kesehatan fisik dan psikologis. Menurut Nelson et al. (2012), sekitar 33,7\% remaja mengalami setidaknya satu diagnosis masalah kesehatan fisik dalam 3 bulan terakhir. Sedangkan menurut WHO (2014), sekitar 10\%-20\% remaja dan anak-anak di dunia mengalami gangguan kesehatan jiwa. Dari data tersebut dapat dilihat bahwa prevalensi masalah kesehatan fisik masih lebih tinggi dibandingkan dengan gangguan kesehatan jiwa.

Gangguan perilaku makan merupakan salah satu masalah kesehatan fisik yang cukup banyak terjadi pada remaja. Tercatat bahwa sekitar 17,8\% remaja di Yunani mengalami gangguan perilaku makan (Bacopoulou et al., 2017). Hal ini tidak berbeda jauh dengan apa yang diteliti oleh Micali, Horton, Crosby, Swanson, Sonneville, Solmi (2017), yang menemukan bahwa sekitar $12,5 \%$ remaja mengalami gangguan perilaku makan. Gangguan perilaku makan didefinisikan sebagai perilaku makan abnormal yang dapat menyebabkan terjadinya gangguan makan (Bryla, 2003). Perilaku makan abnormal tersebut diantaranya pembatasan asupan makanan, sengaja melewatkan waktu makan, memuntahkan makanan dengan sengaja, dan perilaku diet ketat (Zullig, MatthewsEwald, \& Valois, 2016; Gonsalves, Hawk, \& Goodenow, 2014).

Gangguan perilaku makan dapat dipengaruhi oleh faktor biologis, individu, kelompok, keluarga, sosiokultural, dan psikologis. Beberapa faktor yang sudah cukup banyak diteliti dan diketahui memiliki hubungan dengan gangguan perilaku makan yaitu ketidakpuasan terhadap bentuk tubuh, harga diri rendah, media massa, sosiokultural, pola attachment, trauma, dan ketidakstabilan emosi (Andreescu, 2015; Nevins, 2017; Lee \& Vaillancourt, 2018; Lopez, Corona, \& Halfond, 2013; Lai et al., 2013). Faktor lain masih cukup bervariasi hasil penelitiannya yaitu terkait tingkat attachment remaja dengan orang lain. Sejauh ini attachment remaja dikaitkan pada orangtua dan peer, hal ini karena karakteristik remaja yang mulai menambahkan peer sebagai figur yang dekat dengan dirinya namun dengan tidak melepaskan figur orangtua (Hockenberry \& Wilson, 2015). Beberapa penelitian menyatakan adanya hubungan attachment yang tidak kuat dengan gangguan perilaku makan (Lopez, Corona, Halfond, 2013; Dziedzic, 2014; Keel et al., 2013; Kraft, 2009). Sedangkan penelitian ini menyatakan tidak adanya hubungan peer dan/atau parent attachment dengan gangguan perilaku makan pada remaja (Raap, 2015; Ty \& Francis, 2013).

Attachment didefinisikan sebagai sebuah ikatan afektif abadi yang dikarakteristikkan dengan kecenderungan seseorang untuk mencari dan mempertahankan kedekatan figur spesifik, terutama saat dalam masalah (Bowlby, 1969). Teori yang pertam kali dikembangkan oleh John Bowlby ini kemudian dikembangkan lagi oleh Armsden 
\& Greenberg (1987), yang berfokus pada implikasi optimal serta tidak optimalnya attachment terhadap kesehatan psikologis anak dan remaja. Hal ini karena attachment memiliki pengaruh yang penting bagi remaja untuk mampu mengatasi tantangantantangan yang dialami akibat perubahan (De Paoli, Fuller-Tyszkiewicz, \& Krug, 2017). Terlebih lagi, kualitas attachment yang kuat akan menjadi faktor penting bagi remaja dalam menyelesaikan tugas perkembangan yang ada (Gander, Sevecke, \& Buccheim, 2015). Sebaliknya, ikatan attachment yang tidak kuat akan menjadi faktor risiko terbentuknya ansietas, depresi, isolasi sosial, dan perilau bullying (Lee et al., 2017; Charalampus et al., 2018).

Awalnya, attachment berfokus pada ikatan orangtua dengan anak (Bowlby, 1969). Namun seiring bertambahnya usia, figur luar selain orangtua mulai membentuk ikatan afektif yang erat dan hal ini dimulai sejak remaja (Armsden \& Greenber, 1987). Meskipun begitu, attachment remaja dengan peer tidak dianggap sebagai ikatan yang lebih kuat atau lebih bijak dari orangtua, melainkan sebagai attachment yang bersifat sementara dan situasional (Bowlby, 1982). Hal ini karena remaja memiliki kecenderungan untuk lebih mendekatkan dirinya dengan peer karena peer dirasa mampu untuk mendukung dan mendorong remaja menghadapi tugas perkembangan yang dialami (Armsden \& Greenberg, 1987). Untuk itu penelitian ini melibatkan peer sebagai figur tambahan yang memiliki ikatan afektif kuat dengan remaja

Penelitian terkait hubungan peer dan/atau parent attachment dengan gangguan perilaku makan beberapa kali telah diteliti di berbagai negara dengan hasil yang cukup bervariasi. Sebagian besar penelitian menyatakan bahwa remaja dengan attachment tidak kuat memiliki kecenderungan memiliki gangguan perilaku makan (Lopezz, Corona, Halfond,
2013; Dziedzic, 2014; Keel et al., 2013; Kraft, 2009). Sedangkan terdapat sebagian kecil penelitian mendapatkan remaja dengan gangguan perilaku makan tetap memiliki attachment yang kuat dengan peer dan parent (Eisenberg \& Neumark-Sztainer, 2010). Untuk itu, peneliti tertarik untuk meneliti hubungan peer dan parent attachment dengan gangguan perilaku makan.

\section{METODE}

Responden pada penelitian ini adalah remaja berusia 15-17 tahun yang sedang menjalani studi di SMA Negeri 3 Bekasi. Sampel dipilih berdasarkan teknik purposive sampling. Kriteria inklusi penelitian ini yaitu remaja kelas $X$ dan XI yang aktif secara administratif di SMA Negeri 3 Bekasi, berusia 15 hinga 17 tahun, dan mengalami gangguan perilaku makan berdasarkan instrumen EAT26 dengan skor $\geq 20$. Guna mendapatkan sampel sesuai kriteria inklusi, penelitia melakukan screening perilaku makan menggunakan instrumen EAT-26. Screening ini diperlukan untuk mendapatkan sampel yang mengalami gangguan perilaku makan. Responden memenuhi kriteria inklusi diminta kembali untuk berpartisipasi menjadi sampel penelitian. Jumlah responden penelitian ini sebesar 65 siswa yang terbagi menjadi 25 siswa kelas $\mathrm{X}$ dan 40 siswa kelas $\mathrm{XI}$. Seluruh siswa bersedia berpartisipasi dalam penelitian ini dan tidak ada yang mengalami drop out.

The Eating Attitudes Test-26 (EAT26) merupakan instrumen skrining risiko gangguan makan yang dikembangkan oleh Garner (1982), untuk mengukur perilaku makan abnormal dalam dimensi dieting, bulimia \& food preoccupation, dan oral control. Alat ukur ini berisikan 26 item pertanyaan dengan 25 item pertanyaan favorable dan 1 item pertanyaan unfavorable. Pilihan jawaban dan skor untuk pertanyaan favorable adalah 
selalu (skor 3), biasanya (skor 2), sering (skor 1), kadang-kadang (skor 0), jarang (skor 0), dan tidak pernah (skor 0). Sedangkan untuk item pertanyaann unfavorable yaitu selalu (skor 0), biasanya (skor 0), sering (skor 0), kadang-kadang (skor 1), jarang (skor 2), dan tidak pernah (skor 3). Remaja dengan total skor $\geq 20$ dinyatakan mengalami gangguan perilaku makan.

The Inventory of Peer and Parent Attachment (IPPA) pertama kali dikembangkan oleh Armsden \& Greenberg pada tahun 1987. Alat ukur ini digunakan untuk menilai attachment remaja terhadap peer dan orangtua. Alat ukur ini terbagi menjadi IPPA peer version dan IPPA parent version. Alat ukur IPPA peer version berisikan 25 item pertanyaan yang terbagi dalam dimensi komunikasi, dimensi kepercayaan, dan dimensi alienasi. Sedangkan alat alat ukur pertanyaan yang terbagi dalam dimensi komunikasi, dimensi kepercayaan, dan dimensi alienasi. Alat ukur ini menggunakan skala likert dari 1 hingga 5 dengan pilihan jawaban tidak pernah (skor 1), jarang (skor 2), kadang-kadang (skor 3), sering (skor 4), dan selalu (skor 5). Item pertanyaan dimensi komunikasi dan kepercayaan dapat dilakukan scoring secara langsung karena merupakan item pertanyaan favorable. Sedangkan untuk dimensi alienasi perlu dilakukan pembalikan skor sebelum dilakukan scoring karena merupakan item pertanyaan unfavorable. Hasilnya, semakin tinggi jumlah skor diperoleh maka semakin tinggi attachment yang dirasakan oleh remaja terhadap peer dan orangtua

Penelitian ini telah lolos kaji etik oleh Komite Etik Penelitian Fakultas IImu Keperawatan Universitas Indonesia. Alat ukur EAT-26 dan IPPA dinyatakan valid dan reliabel berdasarkan uji validitas dan reliabilitas yang dilakukan oleh peneliti.
Untuk menguji validitas instrumen, peneliti menggunakan uji Pearson Product Moment ( $r$ ) yang membandingkan $r$ hitung dengan $r$ tabel. Sedangkan untuk uji reliabilitas instrumen dilakukan dengan menggunakan metode Alpha Cronbach. Koefisien Alpha EAT-26 sebesar 0,837 dengan validitas $0,364 \mathrm{~s} / \mathrm{d}$ 0,848. Koefisien Alpha IPPA parent version sebesar 0,863 dengan validitas 0,390 s/d 0,688. Sedangkan koefisien Alpha IPPA peer version sebesar 0,862 dengan validitas $0,375 \mathrm{~s} / \mathrm{d} 0,858$.

Analisis hubungan parent attachment dengan gangguan perilaku makan dilakukan dengan menggunakan uji pearson correlation karena kedua variabel terdistribusi tidak normal. Sedangkan analisis hubungan peer attachment dengan gangguan perilaku makan dilakukan dengan menggunakan uji pearson correlation karena salah satu variabel terdistribusi normal.

\section{HASIL}

\section{Karakteristik}

Gangguan perilaku makan mayoritas dialami oleh perempuan $(63,1 \%)$ dengan rata-rata usia responden yaitu 16,15 (SD $0,643)$. Mayoritas nilai indeks massa tubuh berada pada rentang normal $(81,5 \%)$. Saat ini seluruh responden (100\%) tinggal dengan orangtua. Berdasarkan riwayat masalah gastrointestinal seperti nyeri ulu hati, maag, atau buang air besar berdarah dalam 3 bulan terakhir didapatkan sebanyak $53,8 \%$ responden mengalami masalah tersebut.

Nilai rata-rata gangguan perilaku makan yang diperoleh yaitu 23,558. Remaja dinyatakan mengalami gangguan perilaku makan jika memiliki jumlah nilai dalam rentang 20-72. Rata-rata skor peer attachment dan parent attachment yaitu masing-masing 87,08 dan 96,11 (Tabel 1). 
Tabel 1 Distribusi rerata gangguan perilaku makan, peer attachment, dan parent attachment

\begin{tabular}{lcccc}
\hline \multicolumn{1}{c}{ Variabel } & Mean & Median & SD & $\mathbf{9 5 \%} \mathbf{C l}$ \\
\hline Gangguan perilaku makan & 23,558 & 32 & 3,33 & $22,37-24,91$ \\
\hline Peer attachment & 87,08 & 86 & 12,97 & $80,71-89$ \\
\hline Parent attachment & 96,11 & 99 & 14,06 & $92-100,49$ \\
\hline
\end{tabular}

\section{Hubungan peer attachment dengan gangguan perilaku makan.}

Secara umum, pada tabel 2 dapat dilihat adanya hubungan yang signifikan dengan tingkat korelasi yang sedang $(r=0,459$, $p<0,001)$. Dengan demikian, $\mathrm{H}_{\mathrm{a}}$ diterima. Hasil pengujian ini juga menunjukkan adanya hubungan yang positif antara kelekatan remaja dengan peer terhadap gangguan perilaku makan, dimana semakin tinggi kelekatan remaja dengan peer, semakin tinggi pula kecenderungan remaja untuk mengalami gangguan perilaku makan.

Tabel 2 Analisis hubungan peer attachment dengan gangguan perilaku makan

\begin{tabular}{ccc}
\hline \multirow{2}{*}{ Variabel } & \multicolumn{2}{c}{ Gangguan Perilaku Makan } \\
\cline { 2 - 3 } & $\boldsymbol{p}$ value & $\boldsymbol{r}$ value \\
\hline Peer attachment & $<0,001$ & $0,459^{*}$ \\
\hline
\end{tabular}

*po,05 (2-tailed)

Hubungan parent attachment dengan gangguan perilaku makan

Secara umum terlihat adanya hubungan yang signifikan dengan tingkat korelasi yang rendah $(r=0,288, p=0,020)$ (Tabel 3). Dengan demikian, $\mathrm{H}_{\mathrm{a}}$ diterima. Hasil pengujian ini juga menunjukkan adanya hubungan yang positif antara kelekatan remaja dengan orangtua terhadap gangguan perilaku makan, dimana semakin tinggi kelekatan remaja dengan orangtua, semakin tinggi pula kecenderungan remaja untuk mengalami gangguan perilaku makan.

Tabel 3 Analisis hubungan parent attachment dengan gangguan perilaku makan

\begin{tabular}{ccc}
\hline \multirow{2}{*}{ Variabel } & \multicolumn{2}{c}{ Gangguan Perilaku Makan } \\
\cline { 2 - 3 } & $\boldsymbol{p}$ value & $\boldsymbol{r}$ value \\
\hline Parent attachment & 0,020 & $0,288^{*}$ \\
\hline$* 0,05$ (2-tailed) &
\end{tabular}

\section{DISKUSI}

\section{Hubungan peer attachment dengan gangguan perilaku makan}

Penelitian-penelitian sebelumnya yang meneliti hubungan attachment remaja dengan gangguan perilaku makan menemukan bahwa semakin rendah attachment yang dipersepsikan remaja dengan peer maka semakin tinggi kecenderungan remaja mengalami gangguan perilaku makan. Penelitian-penelitian tersebut dilakukan terhadap populasi remaja di suatu tempat secara keseluruhan, sehingga tidak dilakukan secara khusus pada remaja yang telah mengalami gangguan perilaku makan. Penelitian yang dilakukan oleh Keel et al. (2013), menyatakan bahwa semakin rendah attachment yang dipersepsikan remaja dengan peer maka semakin tinggi kecenderungan remaja mengalami gangguan perilaku makan. Hal ini serupa dengan penelitian yang De Paoli, Fuller-Tyszkiewicz, \& Krug (2017), yang menyatakan adanya hubungan yang signifikan antara attachment tidak aman terhadap peer dengan gangguan 
perilaku makan pada remaja. Dengan kata lain, ditemukan arah hubungan yang negatif antara peer attachment remaja dengan gangguan perilaku makan.

Penelitian ini menemukan arah yang sebaliknya yakni arah hubungan yang positif antara peer attachment dengan gangguan perilaku makan. Sehingga penelitian ini menemukan hasil hubungan yang berbeda dengan sebagian besar penelitian terkait sebelumnya. Namun terdapat sedikit penelitian yang menemukan hasil yang sama yakni ditemukan arah yang positif antara peer attachment dengan gangguan perilaku makan. Penelitian tersebut dilakukan oleh Eisenberg \& Neumark-Sztainer (2010), yang menemukan bahwa ada hubungan yang signifikan antara perilaku diet ketat yang dilakukan peer dengan gangguan perilaku makan remaja. Hal ini menunjukkan bahwa kedekatan remaja dengan peer dapat memengaruhi perilaku diri sendiri, sehingga semakin dekat remaja peer yang melakukan perilaku diet ketat dapat meningkatkan kemungkinan remaja mengalami gangguan perilaku makan.

Keinginan remaja untuk tetap mempertahankan perilaku makan yang tidak sehat salah satunya dipengaruhi oleh motivasi dari orang lain. Menurut Kamus Besar Bahasa Indonesia (2014), motivasi adalah sebuah upaya yang dilakukan seseorang untuk mencapai tujuan yang diinginkan. Motivasi yang diberikan oleh peer atau dilakukan bersama dengan peer menjadikan remaja tetap mempertahankan perilaku makan yang terganggu. Menurut Eisenberg et al. (2016), motivasi dari orang lain khususnya peer memiliki hubungan yang signifikan dengan terjadinya gangguan perilaku makan. Penelitian ini juga menunjukkan bahwa motivasi dari peer memiliki pengaruh yang lebih besar bagi remaja dengan harga diri rendah. Sehingga dapat diketahui mengapa remaja dengan attachment yang erat dengan peer tetap mengalami gangguan perilaku makan.

\section{Hubungan parent attachment dengan gangguan perilaku makan}

Penelitian-penelitian sebelumnya yang meneliti hubungan attachment remaja dengan gangguan perilaku makan menemukan bahwa semakin rendah attachment yang dipersepsikan remaja dengan orangtua maka semakin tinggi kecenderungan remaja mengalami gangguan perilaku makan. Penelitian-penelitian tersebut dilakukan terhadap populasi remaja di suatu tempat secara keseluruhan, sehingga tidak dilakukan secara khusus pada remaja yang telah mengalami gangguan perilaku makan. Penelitian yang dilakukan oleh Almenara, Umemura, \& Macek (2016) menyatakan bahwa semakin rendah attachment yang dipersepsikan remaja dengan orangtua maka semakin tinggi kecenderungan remaja mengalami gangguan perilaku makan. Hal ini serupa dengan penelitian yang Koskina \& Giovazolias (2010), yang menyatakan adanya hubungan yang signifikan antara attachment tidak aman terhadap orangtua dengan gangguan perilaku makan pada remaja. Dengan kata lain, ditemukan arah hubungan yang negatif antara parent attachment remaja dengan gangguan perilaku makan.

Penelitian ini menemukan arah yang sebaliknya yakni arah hubungan yang positif antara parent attachment dengan gangguan perilaku makan. Sehingga penelitian ini menemukan hasil hubungan yang berbeda dengan sebagian besar penelitian terkait sebelumnya. Namun terdapat beberapa penelitian yang menemukan hasil yang sama yakni ditemukan arah yang positif antara parent attachment dengan gangguan perilaku makan. Penelitian tersebut dilakukan oleh Boone (2013) yang menemukan bahwa 
remaja yang mengalami gangguan perilaku makan memiliki attachment yang tinggi dengan orangtua. Penelitian tersebut juga menemukan bahwa anak dan orangtua memiliki kualitas komunikasi yang rendah serta kualitas keterasingan yang tinggi dirasakan remaja.

Penelitian ini memiliki keterbatasan. Pertama, penelitian ini lebih banyak berfokus pada upaya remaja dalam menurunkan berat badan dengan mengurangi asupan makanan. Hal ini sesuai dengan remaja perempuan cenderung menginginkan tubuh yang kurus meskipun indeks massa tubuh normal. Sebaliknya, hal ini kurang sesuai untuk remaja laki-laki, karena gangguan perilaku makan yang dilakukan cenderung untuk meningkatkan berat badan dan membentuk badan menjadi lebih muskular. Sehingga perilaku makan abnormal yang ditunjukkan ialah makan yang berlebihan serta olahraga yang ekstrem. Meskipun begitu, penelitian ini menunjukkan adanya remaja laki-laki yang mengalami gangguan perilaku makan. Selain itu, desain penelitian cross sectional yang digunakan peneliti tidak dapat menggambarkan hubungan sebab akibat gangguan perilaku makan dengan parent attachment dan peer attachment

\section{SIMPULAN}

Penelitian ini menemukan bahwa remaja yang memiliki attachment yang kuat dengan peer dan orangtua juga memiliki kemungkinan untuk mengalami gangguan perilaku makan. Hal ini karena kedekatan remaja dengan figur peer mempertahankan motivasi remaja untuk mencapai ideal tubuh kurus yang diinginkan yang berdampak pada terganggunya perilaku makan yang dilakukan. Sedangkan orangtua mempengaruhi motivasi remaja melalui komunikasi dua arah yang didapatkan kurang dirasakan remaja. Penelitian ini merekomendasikan pemerintah khususnya
Kementrian Kesehatan dan sekolah untuk menerapkan pembiasaan perilaku hidup bersih dan sehat (PHBS) dengan memaksimalkan fungsi Unit Kesehatan Sekolah (UKS). Trias UKS dapat dijadikan dasar untuk melakukan berbagai pembinaan secara berkala berkaitan dengan berat badan ideal, perilaku makan yang sehat, dan gizi seimbang. Pembinaan ini dilakukan sebagai upaya meningkatkan dan mempertahankan kesehatan fisik remaja.

Guru BK berperan dalam meningkatkan kesehatan psikologis remaja dengan mengadakan konseling dan menjadi pendamping yang siswa yang dapat dipercaya. Untuk itu, perlu diadakannya pelatihan konseling bagi guru BK akan mampu menjadi konselor yang sesuai dengan kebutuhan remaja sehingga guru BK perlu mengembangkan diri dengan mengikuti berbagai pelatihan konselor yang diadakan oleh pemerintah, swasta atau bahkan sekolah.

\section{UCAPAN TERIMA KASIH}

Peneliti mengucapkan terima kasih kepada pihak sekolah karena telah menginjinkan peneliti untuk melakukan penelitian di SMA Negeri 3 Bekasi. Peneliti juga mengucapkan terimakasih kepada seluruh siswa SMA Negeri 3 Bekasi khususnya kelas X dan XI yang telah bersedia untuk berpartisipasi pada penelitian ini.

\section{DAFTAR PUSTAKA}

Almenara, C. A., Umemura, T., \& MacEk, P. (2016). Parent-daughter relationships and disordered eatingamong emergingadult women from the czech republic. Studia Psychologica, 58(3): 216-230.

Andreescu, A. C. (2015). Emotion processing deficits in disordered eating behaviours (Order No. 3732265). Available from 
ProQuest Dissertations \& Theses Global. (1734465521). Retrieved from https://remote-lib.ui.ac.id:2063/docview /1734465521 ?accountid=17242

Armsden, G. C., \& Greenberg, M. T. (1987). The inventory of parent and peer attachment: Individual differences and their relationship to psychological wellbeing in adolescence. Journal of Youth and Adolescence, 16(5): 427-454.

Bacopoulou, F., Foskolos, E., Stefanaki, C., Tsitsami, E., \& Vousoura, E. (2017). Disordered eating attitudes and emotional/behavioral adjustment in greek adolescents. Eating and Weight Disorders, 1-8.

Boone, L. (2013). Are attachment styles differentially related to interpersonal perfectionism and binge eating symptoms?. Personality and Individual Differences, 54(8): 931-935.

Bowlby, J. (1969). Attachment and loss (2nd ed., Vol. 1). New York: Tavistock Institute of Human Relation.

Bryla, K. Y. (2003). Disordered eating among female adolescents: Prevalence, risk factors, and consequences. Health Educator, 35(2): 25-29.

Charalampous, K., Demetriou, C., Tricha, L., Ioannou, M., Georgiou, S., Nikiforou, M., Stavrinides, P. (2018). The effect of parental style on bullying and cyber bullying behaviors and the mediating role of peer attachment relationships: A longitudinal study. Journal of Adolescence, 64: 109-123.

De Paoli, T., Fuller-Tyszkiewicz, M., \& Krug, I. (2017). Insecure attachment and maladaptive schema in disordered eating: The mediating role of rejection sensitivity. Clinical Psychology and Psychotherapy, 24(6): 1273-1284.

Steinberg, L. (2014). Adolescence (10th ed.). New Yowk: McGraw-Hill.
Dziedzic, A. S. (2014). The relationship of attachment and self-silencing with disordered eating in men (Order No. 3641319). Available from ProQuest Dissertations \& Theses Global; Psychology Database. (1622150089). Retrieved from https://search.proquest. com/docview/1622150089?account $\mathrm{id}=17242$

Eisenberg, M. E. \& Neumark-Sztainer, D. (2009). Friends' dieting and disordered eating behaviors among adolescents five years later: Findings from Project EAT. Journal of Adolescent Health, 47(1): 67-73.

Eisenberg, M. H., Lipsky, L. M., Dempster, K. W., Liu, A., \& Nansel, T. R. (2016). I should but I can't: Controlled motivation and self-efficacy are related to disordered eating behaviors in adolescents with type 1 diabetes. Journal of Adolescent Health, 59(5): 537-542.

Gander, M., Sevecke, K., \& Buchheim, A. (2015). Eating disorders in adolescence: Attachment issues from a developmental perspective. Frontiers in Psychology, 6: 1136.

Garner, D. M., Olmsted, M. P., Bohr, Y., \& Garfinkel, P. E. (1982). The Eating Attitudes Test: psychometric features and clinical correlates. Psychological Medicine, 12, 871-878.

Gonsalves, D., Hawk, H., \& Goodenow, C. (2014). Unhealthy weight control behaviors and related risk factors in massachusetts middle and high school students. Maternal and Child Health Journal, 18(8): 1803-1813.

Hockenberry, M. J. \& Wilson, D. (2015). Wong's nursing care of infants and children (10th Ed). Missouri: Elsevier Mosby.

Kamus Besar Bahasa Indonesia (2016). Kamus besar bahasa Indonesia (KBBI) 
Online-Definisi kata. Motivasi. Retrieved from https://kbbi.kemdikbud.go.id/entri/ motivasi

Keel, P. K., Forney, K. J., Brown, T. A., \& Heatherton, T. F. (2013). Influence of college peers on disordered eating in women and men at 10-year follow-up. Journal of Abnormal Psychology, 122(1): 105-110.

Kementrian Kesehatan Republik Indonesia. (2016). Profil kesehatan indonesia tahun 2015. Diambil dari http://www.depkes. go.id/resources/download/pusdatin/ profil-kesehatan-indonesia/profilkesehatan-Indonesia-2015.pdf

Koskina, N., \& Giovazolias, T. (2010). The effect of attachment insecurity in the development of eating disturbances across gender: The role of body dissatisfaction. Journal of Psychology: Interdisciplinary and Applied, 144(5): 449-471.

Kraft, M. E. L. (2009). A study of parental attachment and eating disorders among female college students (Order No. 3344722). Available from ProQuest Dissertations \& Theses Global. (288250818). Retrieved from https:// search.proquest.com/docview/2882508 18 ? accountid $=17242$

Lai, C. -., Mak, K. -., Pang, J. S., Fong, S. S. M., Ho, R. C. M., \& Guldan, G. S. (2013). The associations of sociocultural attitudes towards appearance with body dissatisfaction and eating behaviors in hong kong adolescents. Eating Behaviors, 14(3): 320-324.

Lee, D. -., Park, J. J., Bae, B. H., \& Lim, H. -. (2018). Moderating effects of preventionfocus on the paths from two insecure attachment dimensions to depression. Journal of Psychology: Interdisciplinary and Applied, 152(3): 151-163.

Lee, K. S. \& Vaillancourt, T. (2018).
Developmental pathways between peer victimization, psychological functioning, disordered eating behavior, and body mass index: A review and theoretical model. Aggression and Violent Behavior, 39: 15-24.

Lopez, V., Corona, R., \& Halfond, R. (2013). Effects of gender, media influences, and traditional gender role orientation on disordered eating and appearance concerns among latino adolescents. Journal of Adolescence, 36(4): 727-736. Micali, N., Horton, N. J., Crosby, R. D., Swanson, S. A., Sonneville, K. R., Solmi, F. (2017). Eating disorder behaviours amongst adolescents: Investigating classification, persistence and prospective associations with adverse outcomes using latent class models. European Child and Adolescent Psychiatry, 26(2): 231-240.

Nelson, T. D., Smith, T. R., Thompson, R. W., Epstein, M. H., Griffith, A. K., Hurley, K. D., Tonniges, T. F. (2012). Prevalence of physical health problems among youth entering residential treatment. Pediatrics, 128(5): e1226-1232.

Nevins, C. (2017). Disordered eating and a history of trauma: The role of interpersonal trust (Order No. 10277633). Available from ProQuest Dissertations \& Theses Global. (1951729941). Retrieved from https://remote-lib.ui.ac.id:2063/docview /1951729941 ?accountid=17242

Raap, S. J. (2015). Connections between parental eating behaviors and adolescents' disordered eating attitudes and behaviors: Optimal parenting style as a mediator (Order No. 1604967). Available from ProQuest Dissertations \& Theses Global. (1747928698). Retrieved from https://search.proquest.com/docvie w/1747928698? accountid=17242

Ty, M. \& Francis, A. J. P. (2013). Insecure 
attachment and disordered eating in women: The mediating processes of social comparison and emotion dysregulation. Eating Disorders, 21(2): 154-174.

World Health Organization. (2014). Health for the world's adolescents: A second chance in the second decade. Retrieved from http://apps.who.int/adolescent/ second-decade/files/1612_MNCAH_ HWA_Executive_Summary.pdf

Zullig, K. J., Matthews-Ewald, M. R., \& Valois, R. F. (2016). Weight perceptions, disordered eating behaviors, and emotional self-efficacy among high school adolescents. Eating Behaviors, 21: 1-6. 